\title{
Perancangan Animasi 3D "Remember" dengan Metode Pose to Pose
}

\author{
Endah Kumala Hadi ${ }^{1}$, Juniardi Nur Fadila ${ }^{2}$, Fresy Nugroho ${ }^{3}$ \\ ${ }^{1}$ Jurusan Teknik Informatika \\ ${ }^{2,3}$ Fakultas Sains dan Teknologi Universitas Islam Negeri Maulana Malik Ibrahim \\ E-mail: ${ }^{1}$ 19650034@ student.uin-malang.ac.id, ${ }^{2}$ juniardi.nur@uin-malang.ac.id , \\ fresy@ti.uin-malang.ac.id
}

\begin{abstract}
Abstrak
Dalam perkembangan dunia teknologi dan informasi, pengaplikasian dari teknologi yang ada pada grafika komputer sangatlah bermanfaat dalam hal visualisasi. Sebuah objek yang nyata dapat divisualisasikan menjadi sebuah bentuk objek grafis. Untuk memberikan informasi yang beragam animasi 3D menjadi pilihan yang sangat tepat. Anak-anak dapat diajarkan sesuatu yang bersifat islami untuk membantu mereka mempelajari agama, yang dapat dikemas dalam sebuah animasi $3 D$ yang menarik. Pada penelitian ini akan membahas mengenai pose to pose pada rancangan animasi yanng berjudul "Remember". Dalam metode ini, gerakan dasar manusia dipraktekkan dengan memanfaatkan objek figur untuk diimplementasikan ke dalam animasi 3D. Pada rancangan animasi 3D akan lebih sering menggunakan tools atau makehuman sebagai pembuatan karakter, yang kemudian akan di import ke software Blender untuk perancangan animasi $3 D$ secara keseluruhan.
\end{abstract}

Kata Kunci-Islami, Animasi 3D, Pose to Pose, Makehuman, Blender

\begin{abstract}
The development of IT improves the benefit of technology application in terms of computer graphics visualization. Moreover, a real object can be visualized into a form of graphic object. Therefore, to provide a variety of information, 3D animation is a very appropriate choice. For instance, children can be taught Islamic content to help them learn more about Islam by packaging the content in an attractive $3 D$ animation. This study focuses on pose to pose in the animation design entitled "Remember". In this method, basic human movements are visualized by utilizing figure objects to be implemented into $3 D$ animation. In $3 D$ animation design, tools namely "makehuman" will be used more frequently to create character, and then being imported into Blender software for overall 3D animation design.
\end{abstract}

Keywords - Islamic, 3D Animation, Pose to Pose, Makehuman, Blender

\section{PENDAHULUAN}

Pada era modern ini, teknologi semakin berkembang pesat. Kemunculan kontenkonten berbasis animasi 2D dan 3D sangatlah signifikan. Animasi menjadi sebuah hiburan yang sangat menarik untuk ditonton karena visualisasinya. Selain itu animasi menjadi dapat menjadi mediahiburan dan pembelajaran bagi anakanak bahkan hingga orang dewasa.
Animasi adalah tampilan urutan gambar dalam ruang 3D sehingga menciptakan iluminasi gerakan. Efeknya dalam gambar harus realistis, sehingga mudah dipahami oleh pengguna. Animasi 3D adalah komputer yang dihasilkan yang memberikan ruang objek. Dalam 3D, gambar dan grafik menggunakan 3 dimensi yang memberikan kedalaman karakter dan presentasi, yang terlihat nyata dan hidup (Ahmed \& Janghel, 2015). 
JURNAL NUANSA INFORMATIKA

Volume 15 Nomor 2, Juli 2021

Sering kali perasaan kecewa muncul dikala suatu hal yang sudah direncanakan tidak sesuai dengan keinginan, kadang kala tidak lepas dari mengeluh dan menggerutu. Padahal, jika diingat kembali, segala yang telah menjadi ketetapan-Nya maka itulah yang terbaik bagi manusia, sebab hanaya Allah yang tahu segala sesuatu yang menjadikan manusia baik Sehingga ketika meminta dan berdoa kepada Tuhan, jangan lupa untuk ikhlas dan pasrah. Kemudian biarkan Tuhan yang menentukan segala sesuatu untuk manusia, lalu percayalah bahwa apa yang Tuhan tetapkan maka itulah yang terbaik. Karena dengan mengingat Tuhan amka hati akan terasa tentram. (QS Ar Ra'ad 13:28) yang Artinya "(yaitu) orangorang yang beriman dan hati mereka manjadi tenteram dengan mengingat Allah. Ingatlah, Hanya dengan mengingati Allahlah hati menjadi tenteram" (Ariadi, 2019).

Tujuan dari dibuatnya animasi 3D berjudul "Remember" ini adalah untuk memberikan hiburan sekaligus pembelajaran bahwa selaga sesuatu mengenai rencana Tuhan itu pasti lebih baik dari segala yang telah direncanakan oleh manusia. Dengan adanya visualisasi animasi 3D ini diharapkan dapat menarik minat penonton untuk diambil manfaatnya dan juga diperhatikan. Pembuatan animasi 3D ini menggunakan software Blender 2.83. 1.1 Animasi

Definisi animasi sendiri berasal dari kata to animate yang berarti menggerakkan, menghidupkan. Misalkan sebuah benda yang mati, lalu digerakkan melalui perubahan sedikit demi sedikit dan teratur sehingga memberikan kesan hidup (Waeo, Lumenta, \& Sugiarso, 2016). Animasi adalah gambar bergerak berbentuk dari sekumpulan objek (gambar) yang disusun secara beraturan mengikuti alur pergerakan yang telah ditentukan (Awulle, Sentinuwo, \& Lumenta, 2016).
p-ISSN : 1858-3911, e-ISSN : 2614-5405

https://journal.uniku.ac.id/index.php/ilkom

Pengertian Animasi Menurut Ibiz Fernandes dalam bukunya Macromedia Flash Animation \& Cartooning: A creative Guide, animasi definisikan sebagai berikut : "Animation is the process of recording and playing back a sequence of stills to achieve the illusion of continues motion" Yang artinya kurang lebih adalah : "Animasi adalah sebuah proses merekam dan memainkan kembali serangkaian gambar statis untuk mendapatkan sebuah ilusi pergerakan." (Sumendap, Tulenan, \& Paturusi, 2019).

\subsection{Animasi 3D}

Animasi 3D atau 3 dimensi adalah proses pembuatan pergerakan gambar dalam lingkaran 3 dimensi. Prinsip kerjanya sama dengan animasi 2 dimensi hanya objek yang dibangun adalah bangun 3 dimensi seperti : Shape, kerucut/cone, kubus dan lain-lain (Satriawan \& Apriyani, 2016).

\subsection{Blender}

Perangkat lunak ini digunakan untuk membuat film animasi, efek visual, model cetak 3D, aplikasi 3D interaktif dan permainan video (Muhammad \& Ahmad, 2020). Hasil program dapat digunakan di komputer lain walaupun tidak menginstall aplikasi blender terlebih dahulu.

\subsection{Metode Pose to Pose}

Pose to pose adalah berisi gambarangambaran keyframe tertentu, selanjutnya untuk meembuat gerakan antara satu pose ke pose lainnya dengan memberikan inbetween agar gerakan terlihat lebih detail (Purwanto, Qodarsih, Majid, \& Syamrahmarini, 2019). Keypose atau pose kunci sendiri merupakan kumpulan gerakan atau pose awal yang menunjukan suatu gerakan tertentu atau biasa disebut gerakan 
JURNAL NUANSA INFORMATIKA

Volume 15 Nomor 2, Juli 2021

utama. Metode pose to pose ini biasanya di gunakan oleh industri animasi karena penggunaan metode ini dalam pembuatan animasi lebih cepat dan dapat memperbaiki kesalahan gerakan atau pose dengan mudah (Salmon, Tulenan, \& Sugiarso, 2017).

\subsection{MakeHuman}

Untuk desain karakter manusia pada makehuman menggunakan Tools Modeling yang terdiri dari main, gender, face, torso, arms and legs, custom, dan measure. Tools tersebut digunakan untuk membentuk tubuh manusia sesuai yang di inginkan (Balamba, Lumenta, \& Sugiarso, 2017)

\section{METODE PENELITIAN}

Terdapat tahapan-tahapan yang harus dilalui dalam proses pembuatan animasi agar mencapai hasil yang maksimal. Tahapantahapan tersebut dimulai dari penentuan konsep cerita dan pembuatan storyboard. Setelah konsep ditentukan proses selanjutnya adalah dengan proses pengambilan gambar yang dipecah menjadi beberapa komponen seperti modeling, rigging, animasi, dan lain sebagainya (Waeo, Lumenta, \& Sugiarso, 2016).

Gambaran dari tahapan dapat dilihat pada gambar 1 .

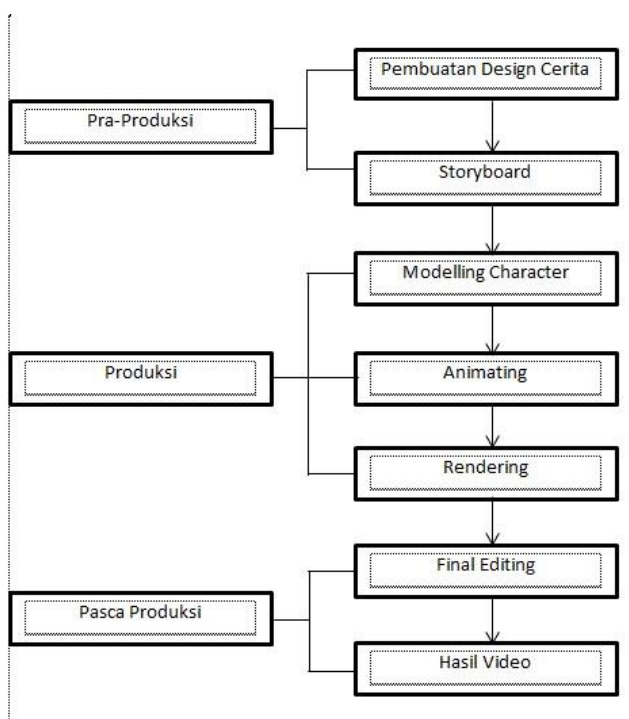

p-ISSN : 1858-3911, e-ISSN : 2614-5405

https://journal.uniku.ac.id/index.php/ilkom

Gambar 1. Tahapan Pembuatan Animasi 3D

\subsection{Pra Produksi}

Pada tahapan pra-produksi terdapat perencanaan, perancangan, dan penelitian dalam semua proses tahapan pembuatan animasi 3D diawal (Firdaus NA, 2019). Kerangka kerja dimulai dari tahap Pra Produksi yaitu proses penentuan ide dan tema, dimana Penulis menentukan ide dan tema ketika menyadari pentingnya mengajarkan peduli lingkungan sejak dini kepada anak-anak (Toding, Lumenta, \& Mamahit, 2017).

\subsubsection{Ide Cerita}

Gagasan serta ide-ide yang unik sangat mahal harganya. Kalau anda sedang mood, mungkin pada waktu yang singkat ide yang unik sudah bisa anda temukan (Syahfitri, 2011).

\subsubsection{Storyboard}

Pada tahapan ini dirancang storyboard untuk menjelaskan secara detail setiap adegan di dalam animasi yang dibuat. Selain itu juga terdapat tabel untuk memberikan spesifikasi efek-efek yang diberikan pada setiap adegan (Wijayanto). Visualisasi dari ide dalam bentuk gambar dilakukan dalam proses ini jika karakter - karakter sudah selesai dibangun, cerita dapat divisualisasikan (storyboard dapat diubah) (Suratinoyo, Wowor, Robot, \& Karouw).

\subsection{Produksi}

Produksi yaitu tahap pembuatan film animasi yang berawal pada pembuatan model yang akan dibuat lalu diwarnai dan kemudian diberikan gerakan atau animasi serta efek khusus. Kemudian setelah diberikan animasi dan efek khusus maka 
JURNAL NUANSA INFORMATIKA Volume 15 Nomor 2, Juli 2021

model tersebut dapat digabungkan menjadi sebuah film. Produksi meliputi: (1) Modeling, (2) Texturing, (3) Compositing, (4) Animating, (5) Rendering (Nari, Rindengan, Tulenan, Sentinuwo, \& Lantang, 2014).

\subsubsection{Modelling}

Biasanya semua pemodelan dimulai dengan pemodelan kubus dan bergerak lebih jauh ke pergerakan masuk dan keluar simpul kubus untuk membuat struktur atau mesh yang lebih besar atau lebih kecil dan rumit. Lain adalah pemodelan dengan kurva yang memberi kita benda-benda seperti dinding dan permukaan datar (Ahmed \& Janghel, 3D Animation: Don't Drink and Drive, 2015).

\subsubsection{Animating}

Pada tahap Animating ini penulis melakukan pengaturan pergerakan objek animasi dengan memberikan gerakan pada objek maupun pada kemera sesuai storyboard (Bentelu, Sentinuwo, \& Lantang, 2016). Animation adalah proses pembuatan gerakangerakan pada model animasi yang disesuaikan dengan adegan dalam storyboard yang ceritanya akan ditampilkan dalam film (Awulle, Sentinuwo, \& Lumenta, 2016).

\subsubsection{Texturing}

Texturing merupakan salah satu hal penting dalam membuat animasi 3D, tujuannya supaya karakter yang dibuat tampak seperti real (Ciarantika, Faradisa, \& Assidiqi). Ini adalah metode di mana kita dapat menambahkan detail kecil ke permukaan yang diberikan dengan memproyeksikan atau memfokuskan gambar pada objek dan beberapa tingkat tekstur pada permukaan objek. Gambar yang digunakan untuk proyeksi mengubah warna objek, SRT (specular-reflection-
p-ISSN : 1858-3911, e-ISSN : 2614-5405

https://journal.uniku.ac.id/index.php/ilkom

transparency) objek. Tekstur dapat berlaku untuk berbagai hal seperti bahan, adegan dunia untukmenciptakan awan dan warna langit alami untuk pemandangan dan kuas sehingga dapat bekerja sesuai tekstur yang akan diterapkan pada objek (Ahmed \& Janghel, 2015).

\subsubsection{Rigging}

Rigging adalah proses menempelkan kerangka ke model manusia; model manusia disiapkan menggunakan perangkat lunak open source Make Human. Sambungan kerangka harus ditempatkan pada posisi yang sesuai pada model manusia yang dibuat untuk memetakan kerangka karakter rig dengan kerangka kinect yang ditangkap (Shingade \& Ghotkar, 2014).

\subsubsection{Rendering}

Rendering merupakan tahap akhir dari proses produksi. Rendering dilakukan untuk membuat animasi ini kedalam bentuk movie. Proses rendering dilakukan pada setiap adegan satu demi satu hingga menjadi beberapa file, yang selanjutnya dapat di edit menggunakan program ulead video studio 11 untuk penggabungan adegan dan diberikan efek suara (Rinaldi, Rumagit, Lumentas, \& Wowor).

\subsection{Pasca Produksi}

Adalah bagian akhir dalam proyek animasi 3D, namun proses dalam pasca produksi bisa berbeda pada masing-masing studio animasi. Dalam industri hiburan tahap ini digunakan untuk untuk benar-benar membuat sebuah proyek benar-benar menonjol melalui efek dan koreksi warna (Waeo, Lumenta, \& Sugiarso, 2016).

\section{HASIL DAN PEMBAHASAN}


JURNAL NUANSA INFORMATIKA Volume 15 Nomor 2, Juli 2021

Pada bagian hasil dan pembahasan ini akan membahas mengenai proses dan hasil pembuatan animasi 3D yang berjudul "Remember". Proses pembuatan animasi ini dilakukan mulai dari tahap pra-produksi, produksi, hingga pasca produksi.

\subsection{Tahap Pra-Produksi}

\subsubsection{Ide Cerita}

Tema cerita yang telah ditentukan adalah mengenai cerita islami. Sehingga cerita yang dibuat merupakan sebuah cerita yang berunsur islami. Melalui cerita ini diharapkan dapat memberikan pembelajaran pesan moral dan bermanfaat bagi penontonnya.

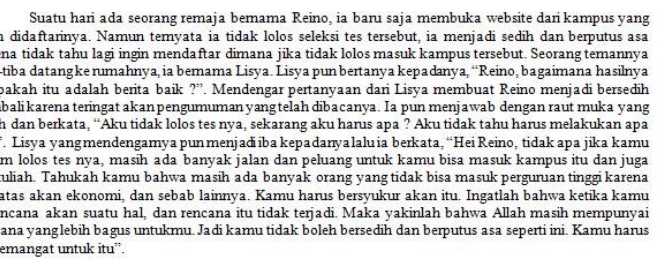

Gambar 3.1.1 Ide Cerita

\subsubsection{Storyboard}

Storyboard merupakan gambar dengan ide yang tertuang didalamnya sehingga dapat memberikan gambaran secara garis besar dari cerita yang akan dihasilkan (Toding, Lumenta, \& Mamahit, 2017). Dengan adanya storyboard, memberi keuntungan bagi pengguna untuk membuat perubahan pada alur cerita untuk menimbulkan kesan yang lebih dalam.
p-ISSN : 1858-3911, e-ISSN : 2614-5405

https://journal.uniku.ac.id/index.php/ilkom
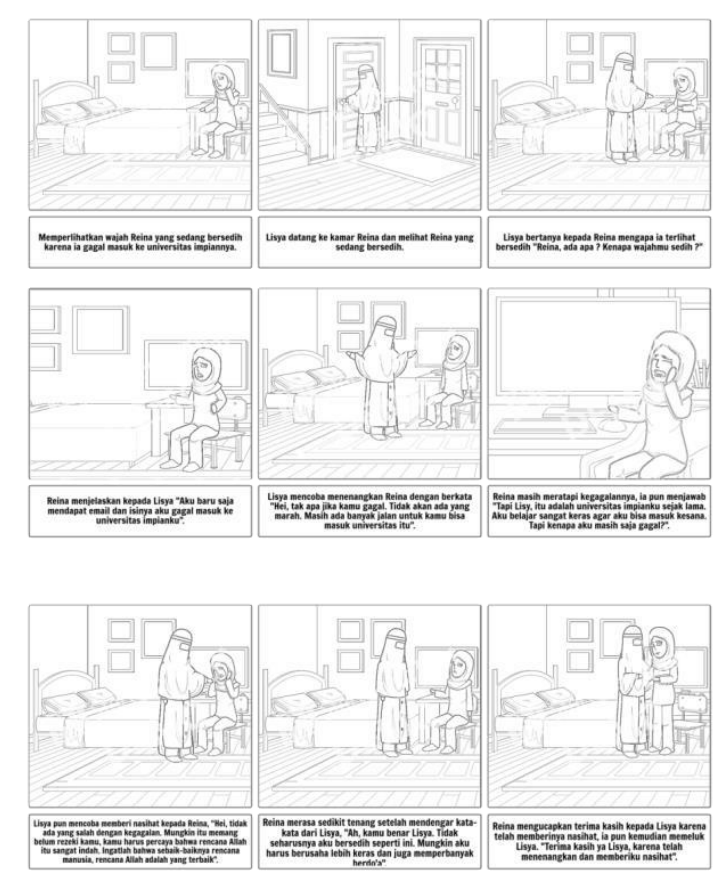

Gambar 3.1.2 Storyboard

\subsection{Tahap Produksi \\ 3.2.1Modelling}

Tahap ini adalah pembuatan objectobject yang dibutuhkan pada tahap animasi, object seperti sebuah karakter dan sebagainya.Pada tahapan ini digunakan 2(dua) software,yaitu Blender dan Makehuman (Awulle, Sentinuwo, \& Lumenta, 2016). Pada tahap ini dilakukan proses modifikasi pada sebuah karakter dan asset yang dibuat, yaitu dengan menggunakan scale, rotation, dan extrude.

\subsubsection{Modelling di Blender}

Pada blender proses pembuatan objek menggunakan tools mesh yang terdiri dari plane, cube, circle, UV sphere, icosphere, cylinder, cone, grid, dan lain-lain yang bisa dipakai sesuai kebutuhan (Awulle,

Sentinuwo, \& Lumenta, 2016). 
JURNAL NUANSA INFORMATIKA

Volume 15 Nomor 2, Juli 2021

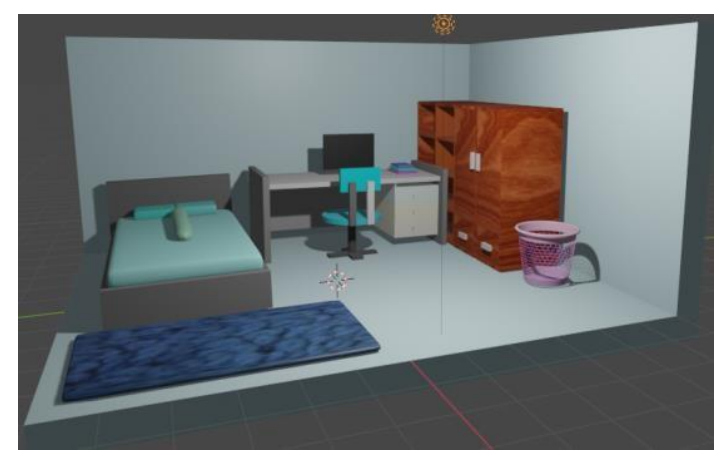

Gambar 3.2.1.1 Modelling Object di Blender

\subsubsection{Modelling di Makehuman}

Untuk desain karakter manusia pada makehuman menggunakan Tools Modeling yang terdiri dari main, gender, face, torso, arms and legs, custom, dan measure.

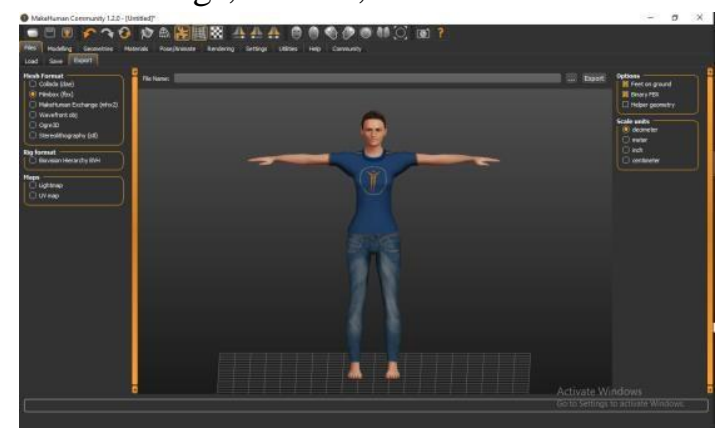

Gambar 3.2.1.2 Modelling Karakter di MakeHuman

\subsubsection{Animating Menggunakan Metode Pose to Pose}

Tahap selanjutnya setelah melakukan proses rigging adalah tahap animating. Metode yang digunakan pada tahap animating ini menggunakan metode pose to pose. Pose to pose sendiri merupakan teknik pengerjaan animasi dengan menambahkan keyframe, untuk membuat gerakan satu pose ke pose yang lain agar lebih detail.
p-ISSN : 1858-3911, e-ISSN : 2614-5405

https://journal.uniku.ac.id/index.php/ilkom

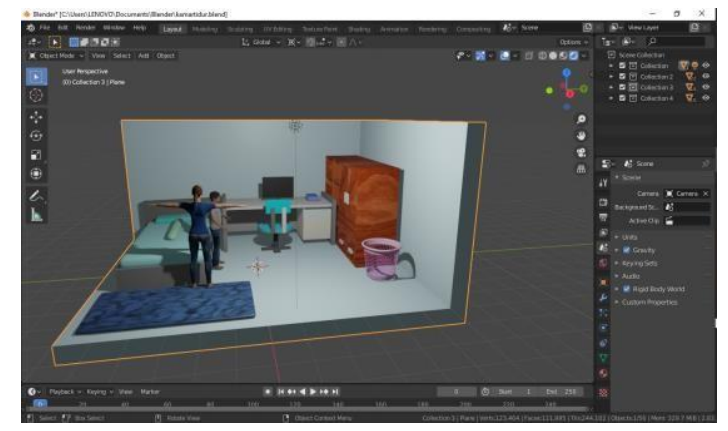

Gambar 3.2.2 Animating

\subsubsection{Rendering}

Tahap rendering merupakan tahap penyatuan dari semua tahap-tahap sebelumnya yang telah dilakukan, sehingga nantinya menjadi sebuah file animasi yang dapat diatur sesuai dengan kebutuhan. Rendering dilakukan pada setiap adegan yang diperlukan untuk ditayangkan dengan melakukan perhitungan estimasi waktu untuk menyelesaikan proses rendering,waktu yang dibutuhkan untuk menyelesaikan proses rendering juga dipengaruhi oleh banyaknya objek dalam sebuah adegan (Awulle, Sentinuwo, \& Lumenta, 2016).

\subsection{Tahap Pasca Produksi}

Tahap ini merupakan tahap terakhir setelah dilakukannya rendering dan menghasilkan sebuah file video animasi. Final Editing ini untuk melihat perbandingan gerakan tariannya. Vidio disusun secara berurutan berdasarkan pedoman gerakan pada video manusia dan storyboard yang dibuat Final editing (Salmon, Tulenan, \& Sugiarso, 2017).

\section{KESIMPULAN}

Video animasi 3D menceritakan bagaimana seorang yang merasa putus asa karena keinginannya tidak tercapai, kemudian kakaknya memberitahu dan mengingatkannya bahwa manusia boleh 
JURNAL NUANSA INFORMATIKA

Volume 15 Nomor 2, Juli 2021

berencana sebaik apapun, namun haruslah jika rencana yang dibuat tidak sesuai maka Allah pasti sudah mempunyai rencana yang lebih baik untuk umatnya. Adanya video animasi ini bertujuan agar penonton selalu percaya akan takdir dan rencana yang sudah disiapkan oleh Tuhan adalah versi terbaik dari rencana manusia. Rencana yang hanya diketahui oleh-Nya. Dalam pembuatan animasi 3D emlalui bebrapa tahapan yaitu tahap pra-produksi, tahap produksi, dan tahap pasca produksi. Tahap pra-produksi dimana dalam tahap ini dilakukakn penentuan design cerita atau ide cerita yang akan dibuat dan storyboard. Sedangkan pada tahap produksi terjadi proses dimana animasi dibuat dengan melakukan modelling karakter dan asset lalu animation dan rendering. Pada proses animating mengunakan metode pose to pose untuk seluruh gerakan karakter pada animasi 3D. Terakhir tahap pasca produksi dimana animasi 3D selesai dibuat dan berbentuk sebauh file video animasi yang dapat ditonton oleh banyak orang.

\section{UCAPAN TERIMA KASIH}

Dalam pembuatan animasi ini, penulis banyak mengucapkan terima kasih kepada dosen pengampu mata kuliah Grafika Komputer yaitu Bapak Fressy Nugroho, M.T dan Bapak Juniardi Nur Fadila, M.T yang telah berkontribusi dalam membimbing proses penyelesaian penelitian sekaligus pembuatan animasi 3D yang telah dilakukan hingga selesai.

\section{DAFTAR PUSTAKA}

Ahmed, I., \& Janghel, S. (2015). 3D Animation: Don't Drink and Drive. International Journal of $u$ - and eService, Science and Technology, 415-426.
p-ISSN : 1858-3911, e-ISSN : 2614-5405

https://journal.uniku.ac.id/index.php/ilkom

Ariadi, P. (2019). Kesehatan Mental dalam Perspektif Islam. Syifa' MEDIKA: Jurnal Kedokteran dan Kesehatan, 118.

Awulle, M. E., Sentinuwo, S. R., \& Lumenta, A. S. (2016). Pembuatan Film

Animasi 3D Menggunakan Metode Dynamic Simulation. E-Journal Teknik Elektro dan Komputer, 7079.

Balamba, M. K., Lumenta, A. S., \& Sugiarso, B. A. (2017). Animasi 3

Dimensi Penyakit Jantung

KoronerPada Manusia. E-Journal

Teknik

Informatika.

Bentelu, A. S., Sentinuwo, S., \& Lantang, O. (2016). Animasi 3 Dimensi Pencegahan Cyber Crime (Studi Kasus : Kota Manado). E-Journal Teknik Informatika, 1-7.

Ciarantika, A., Faradisa, R., \& Assidiqi, M. $\mathrm{H}$.

(t.thn.). PEMBUATAN VIDEO ANIMASI 3D SAFETY DRIVING (NON-CHARACTER

MODELING, TEXTURING, SOUND EFFECTS).

Firdaus NA, F. (2019). SIMULASI GERAK

HEWAN

BURUNG

MENGGUNAKAN METODE

POSE TO POSE DALAM

PEMBUATAN

ANIMASI 3D DALAM SURAT

ALFILL SKRIPSI Oleh : FERLY

FIRDAUS NA. 91.

Muhammad, M., \& Ahmad, A. (2020).

PERANCANGAN ANIMASI

PENGENALAN HURUF

HIJAIYAH BAGI ANAK USIA

DINI 3-4 TAHUN

MENGGUNAKAN APLIKASI 
JURNAL NUANSA INFORMATIKA

Volume 15 Nomor 2, Juli 2021

BLENDER. Journal

Informatic, Education and Management, 110-

117.

Nari, J., Rindengan, Y., Tulenan, V., Sentinuwo, S., \& Lantang, O. (2014).

PERANCANGAN STUDIO

MUSIK BAMBU DENGAN PERSPEKTIF ANIMASI 3D. E-

Journal Teknik

Informatika, 1-7.

Purwanto, I. H., Qodarsih, L., Majid, F. H., \& Syamrahmarini, K. A. (2019). Implementasi Pose To Pose Pada Simulasi Gerak Panda Berjalan Dengan Teknik Frame By Frame.

Jurnal Explore STMIK Mataram, 4346.

Rinaldi, J., Rumagit, A. M., Lumentas, A.

S., \& Wowor, A. (t.thn.).

Perancangan Tutorial

Penerimaan Mahasiswa Baru

Universitas Sam Ratulangi Berbasis

Android 3D. 1-6.

Salmon, S. F., Tulenan, V., \& Sugiarso, B.

A. (2017). Penggunaan Metode

Pose to Pose dalam Pembuatan

Animasi 3D Tarian Minahasa

Maengket. Ejournal Teknik

Informatika, 1-9.

Satriawan, A., \& Apriyani, M. E. (2016).

ANALISIS DAN PEMBUATAN RIGGING KARAKTER 3D PADA

ANIMASI 3D " JANGAN

BOHONG DONG " In the manufacture of $3 \mathrm{D}$ animation there is a process called rigging . Rigging is the method of administration or installation of the bones of the animated character to be $\mathrm{m}$. JURNAL TEKNIK INFORMATIKA, 72-77.

Shingade, A., \& Ghotkar, A. (2014).

Animation of 3D Human Model
p-ISSN : 1858-3911, e-ISSN : 2614-5405

https://journal.uniku.ac.id/index.php/ilkom

Using Markerless.

International Journal of Computer

Graphics \& Animation (IJCGA),

27-39.

Sumendap, I. Y., Tulenan, V., \& Paturusi,

S. D. (2019). Pembuatan Animasi 3

Dimensi Menggunakan

Metode

Multimedia Development Life

Cycle (Studi Kasus : Tarian Dana

Daerah Gorontalo). Jurnal Teknik

Informatika, 227-234.

Suratinoyo, H. S., Wowor, H., Robot, J., \&

Karouw, S. (t.thn.).

CERITA RAKYAT DAERAH

MINAHASA : IMPLEMENTASI

SHORT FILM ANIMASI

3D dan dibutuhkan

kemampuan.

Syahfitri, Y. (2011). Teknik film animasi

dalam dunia komputer.

Jurnal SAINTIKOM, 213-217.

Toding, C., Lumenta, A. S., \& Mamahit, D. J.

(2017). Pembuatan Animasi 3

Dimensi Perbedaan Sampah

Organik dan Anorganik untuk

Anak-Anak. EJournal Teknik

Informatika.

Waeo, V., Lumenta, A. S., \& Sugiarso, B.

A. (2016). Implementasi

Gerakan Manusia Pada Animasi 3D

Dengan Menggunakan

Menggunakan Metode Pose to

pose. E-journal Teknik

Informatika, 1-8.

Wijayanto, A. (t.thn.). PERANCANGAN

ANIMASI 3D DENGAN

MENGGUNAKAN TEKNIK

STOP MOTION DAN PARTICLE

SYSTEM PROGRAM STUDI

TEKNIK INFORMATIKA

UNIVERSITAS TANJUNGPURA

Agung Wijayanto. 